\title{
THE EXTRACELLULAR SPACE IN RED AND WHITE MUSCLES OF THE RAT
}

\author{
Nobuko KoBayashi AND Ken'ichi YonemuRA \\ Department of Physiology, Kumamoto University Medical School, Kumamoto
}

\begin{abstract}
One of the necessary steps for estimating the intracellular sodium and potassium concentrations of muscles is to know the dimension of the extracellular space of muscles as exactly as possible. The ideal method demands an extracellular tag that does not penetrate cells, and from this point of view inulin, a high molecular-weight polysaccharide, is considered to be most satisfactory $^{1)}$. A number of experiments have been reported on the dimension of the inulin space of the soleus muscle (SOL), containing predominantly red muscle fibers, and the extensor digitorum longus muscle (EDL), containing mostly pale muscle fibers, of albino rats as well as of other tissues as representing the extracellular space. SRETER and $\mathrm{WOO}^{8)}$ obtained a value of $8 \%$ for the inulin space of the SOL muscle and $12.5 \%$ for that of the EDL muscle using Wistar-King strain rats. DRAHOTA ${ }^{4}$ reported the values of $11.2 \%$ and $16.3 \%$ for the SOL and EDL, respectively. ZIERLER ${ }^{11)}$ estimated the inulin space of the EDL to be $25.4 \%$, and ZIERLER, ROGUS and HAZLEWOOD $\left.{ }^{12}\right) 21.4 \%$. These appreciable discrepancies in the values obtained for the inulin space of rat muscles seem to be not only due to the difference in the type of muscles, red or white, but also due to the weight of muscles used, because it has been reported that there is a significant negative correlation between the weight of muscles or age of animals and the size of the sucrose space of toad muscles ${ }^{6,9)}$, of the chloride and sodium spaces of Sprague-Dawley strain rats ${ }^{10)}$ and of the sodium and chloride spaces as well as the inter-fiber space, measured by histological studies, in muscles of the man and pig ${ }^{2)}$. Therefore, the measurements of the inulin spaces were performed on the two types of muscles, red and white, with various weights ranging from $23.5 \mathrm{mg}$ to $197.2 \mathrm{mg}$. It will be shown in this paper that the inulin spaces of both the SOL and the EDL change with the muscle weight or age of rats.
\end{abstract}

Received for publication March 24, 1967

小林信子, 米村健一 


\section{MATERIALS AND METHODS}

The soleus (SOL) and extensor digitorum longus (EDL) muscles of Wistar-King strain rats as well as those of Sprague-Dawley strain rats were used in the experiments as representing the red and white muscle, respectively. The experiments were carried out on rats of various ages, whose body weight ranged from $70 \mathrm{~g}$ (23.5 mg in muscle weight) to $395 \mathrm{~g}$ (197.2 $\mathrm{mg}$ in muscle weight). As a measure of the extracellular space the inulin space was chosen in this experiment. The inulin solution for soaking muscles contained $102 \mathrm{mM} \mathrm{NaCl}, 5.0 \mathrm{mM} \mathrm{KCl}, 2.5 \mathrm{mM} \mathrm{CaCl}_{2}, 1.2 \mathrm{mM} \mathrm{MgSO}_{4}, 28.0 \mathrm{mM} \mathrm{NaHCO}_{3}$, $1.2 \mathrm{mM} \mathrm{Na} \mathrm{HPO}_{4}, 0.6 \mathrm{mM} \mathrm{NaH} \mathrm{PO}_{4}$ and $10 \mathrm{~g} / 1$ inulin; the osmotic pressure of the solution was similar to that of the basic saline solution (composition in $\mathrm{mM}: \mathrm{NaCl}$ 114. $0, \mathrm{KCl} 5.0, \mathrm{CaCl}_{2} 2.5, \mathrm{MgSO}_{4} 1.2, \mathrm{NaHCO}_{3} 28.0, \mathrm{Na}_{2} \mathrm{HPO}_{4} 1.2, \mathrm{NaH}_{2} \mathrm{PO}_{4} 0.6$ and glucose 11.0 ). Freshly dissected muscles were soaked at a temperature of $26^{\circ} \mathrm{C}-28^{\circ} \mathrm{C}$ in the inulin solution, aerated with a mixture of $95 \% \mathrm{O}_{2}$ and $5 \% \mathrm{CO}_{2}$, for $2 \mathrm{hr}$, in which time inulin was considered to diffuse into the extracellular space. The muscles were then trimmed, blotted with a filter paper, weighed and soaked for another $2 \mathrm{hr}$ in about $5 \mathrm{ml}$ of the inulin-free saline solution in order that inulin in the muscle diffused into the inulin-free solution. The amount of inulin diffused out in the inulin-free solution was measured spectrophotometrically with a diphenylamine method $\left.{ }^{5}\right)$ : Five $\mathrm{ml}$ of solution containing inulin from the muscle was diluted with inulin-free solution up to $10 \mathrm{ml}$, and to $2 \mathrm{ml}$ of this solution was added $4 \mathrm{ml}$ of $1.9 \%$ diphenylamine reagent in a test tube. The mixture was shaken for a few min, left in a warm bath for further $30 \mathrm{~min}$ and then left finally for 10-15 $\mathrm{min}$ at room temperature for the analysis of inulin. A reagent blank was obtained by adding $4 \mathrm{ml}$ of $1.9 \%$ diphenylamine reagent to deionized water. Spectrophotometric analyses were conducted by use of the Shimazu photoelectric spectro-photometer (QB-50) at the wave length of $620 \mathrm{~m} \mu$.

\section{RESULTS}

Correlation of the muscle weight to body weight. FIG. 1 shows that there is an approximately linear relation between muscle weights and body weights, EDLs of both Wistar-King strain and Sprague-Dawley ly on a straight line, while SOLs of both strains ly on a line, having a slope smaller than that for EDLs. This indicates that the growth rate of the muscle weight is faster in the EDL than in the SOL. Though it is not very clearly seen in the figure, the muscle weight seems to begin to saturate over $300 \mathrm{~g}$, the age for which is assumed to be over three months old in the Wistar-King strain rats ${ }^{8}$.

Dry-to-wet-weight ratio. The dry-to-wet-weight ratio of both EDLs and SOLs are presented in FIG. 2. No clear change in the ratio with a change in the weight is seen in the figure. The mean of the dry-to-wet-weight ratios is 0.222 for the EDL and 0.217 for the SOL of Wistar-King strain rats, and 0.226 for the EDL and 0.227 for the SOL of Sprague-Dawley strain rats. However, the variabity of the ratios is relatively large in the muscles of a small wet weight, and in the Wistar-King strain rats the ratios for EDLs and for SOLs tend to become small with decreasing weight. In agreement with this VERNADAKIS and WOODBURY ${ }^{10}$ ) have reported that the percentage of muscle 


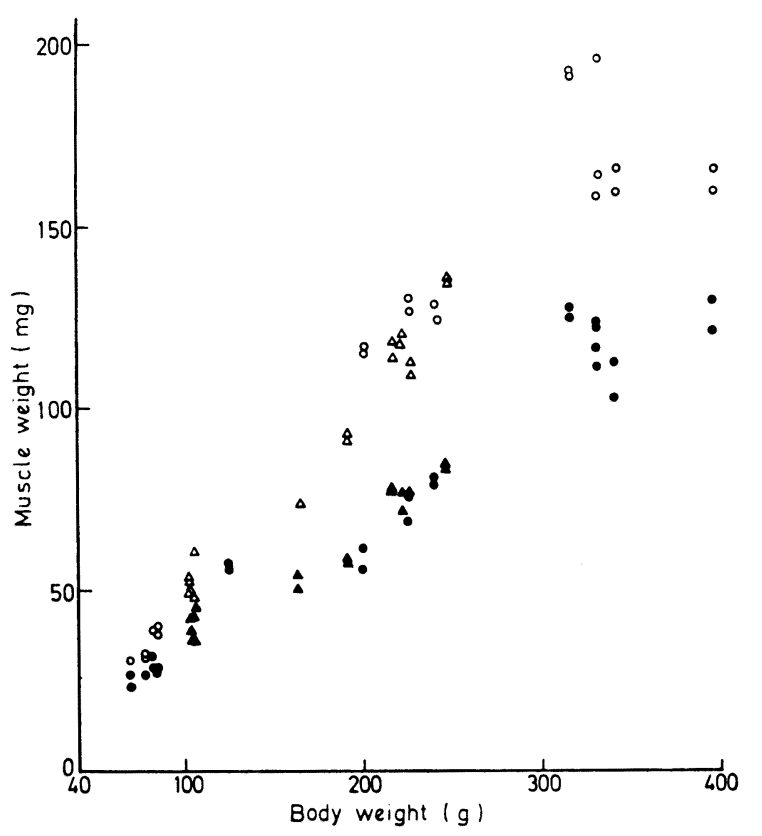

FIG. 1. Relationship between the muscle weight and the body weight.

O; EDL (W.K. rats), O SOL (W.K. rats),

$\triangle ; \operatorname{EDL}$ (S. D. rats) and $\Delta$; SOL (S. D. rats).

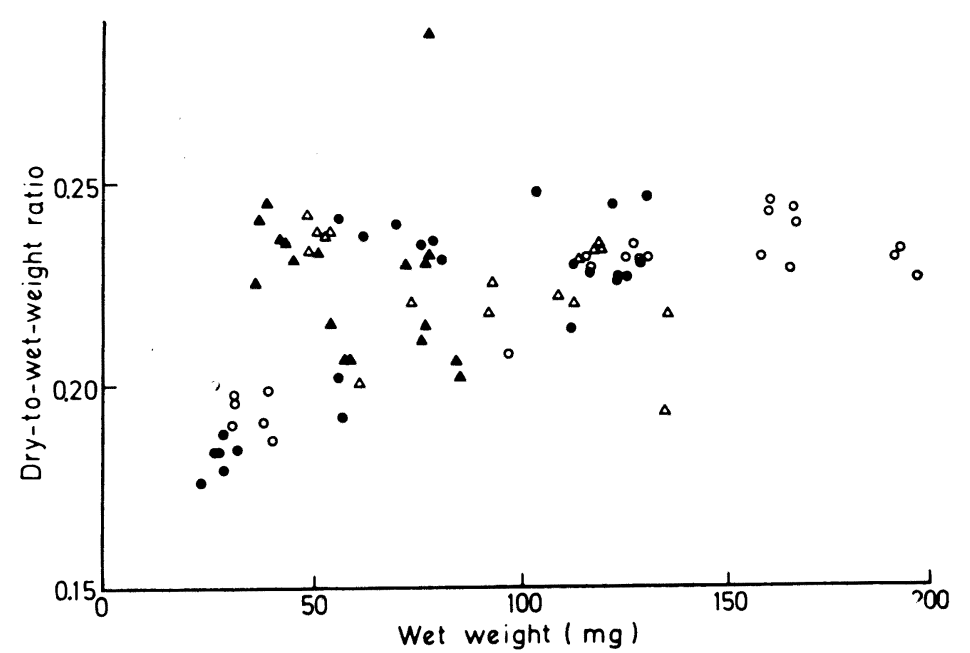

FIG. 2. Relationship between the dry-to-wet-weight ratio and the wet weight.

O; EDL (W.K. rats), O SOL (W.K. rats),

$\triangle ; \operatorname{EDL}$ (S. D. rats) and $\Delta$; SOL (S. D. rats). 
total $\mathrm{H}_{2} \mathrm{O}$ decreases progressively during maturation of Sprague-Dawley strain rats. The reason why no systematic trend of changes in the ratio with increasing wet weight can not be found in FIG. 1 may be explained by the difference in the muscle weight or age of rats used in the present experiments from that by VERNADAKIS and WOODBURY ${ }^{10)}$, because they observed changes in muscle total $\mathrm{H}_{2} \mathrm{O}$ most notably with rats below one month old, whereas the rats used in present experiments were about one month old or older.

Therefore, the values for EDLs and SOLs of Wistar-King strain having a wet weight of less than $50 \mathrm{mg}$ were excluded from the mean, and the results are shown in TABLE 1.

Difference in the inulin space between SOLs and EDLs. Comparison of the spaces between SOLs and EDLs, which were obtained from the same individuals, was made in Wistar-King strain rats as well as in Sprague-Dawley strain rats. The results are shown in TABLE 2. The mean value for the inulin space of EDLs is smaller than that for SOLs in both strains, whereas the muscle weight of EDLs is greater than that of SOLs. These differences are statistically significant, and are in agreement with the previous findings ${ }^{4,8}$.

Variation in space and its correlation to muscle weight. Although the average values of the inulin spaces of 20 SOLs and that of 20 EDLs are 11.1士 $1.04 \mathrm{ml} / 100 \mathrm{~g} \mathrm{w} . \mathrm{w}$. and $9.7 \pm 0.84 \mathrm{ml} / 100 \mathrm{~g} \mathrm{w}$. w. respectively, a great variation

TABLE 1.

The dry-to-wet-weight ratio of EDLs and SOLs.

\begin{tabular}{l|c|c|c}
\hline Muscles & Wistar-King & Sprague-Dawley & Mean \\
\hline EDL & $0.233 \pm 0.0021(16)$ & $0.226 \pm 0.0035(17)$ & $0.229 \pm 0.0021(33)$ \\
SOL & $0.230 \pm 0.0041(18)$ & $0.227 \pm 0.0045(18)$ & $0.228 \pm 0.0029(36)$ \\
EDL+SOL & $0.231 \pm 0.0023(34)$ & $0.226 \pm 0.0028(35)$ & \\
\hline
\end{tabular}

\pm Refers to S.E. of the mean.

Numerals inside the parentheses indicate the number of muscles, which had a wet weight of more than $50 \mathrm{mg}$ in Wistar-King rats.

TABLE 2.

Inulin space of SOLs and EDLs.

\begin{tabular}{c|c|c} 
Muscles & $\begin{array}{c}\text { Space } \\
\text { (ml/100 g w.w.) }\end{array}$ & $\begin{array}{c}\text { Weight range } \\
(\mathrm{mg})\end{array}$ \\
\hline W. K. SOL (20) & $11.1 \pm 1.04$ & $23.3-131.1$ \\
W. K. EDL (20) & $9.7 \pm 0.84$ & $30.5-197.2$ \\
S. D. SOL (17) & $14.3 \pm 1.12$ & $36.4-85.0$ \\
S.D. EDL (17) & $11.7 \pm 0.75$ & $39.3-134.5$ \\
\hline
\end{tabular}

\pm Refers to S.E. of the mean.

Numerals inside the parentheses indicate the number of muscles. 
was observed among the space values in both kinds of muscles. The dimension of the space ranged from $5.9 \mathrm{ml} / 100 \mathrm{~g} \mathrm{w}$. w. to $16.0 \mathrm{ml} / 100 \mathrm{~g} \mathrm{w}$. w. in the EDL and from $6.7 \mathrm{ml} / 100 \mathrm{~g} \mathrm{w}$. w. to $21.5 \mathrm{ml} / 100 \mathrm{~g} \mathrm{w}$. w. in the SOL. The variability in the space of the EDL as well as in the SOL is considered to be due to a variation in the muscle weight, as seen in other tissue ${ }^{26.9910)}$. In FIG. 3 the inulin space was plotted against the muscle weight of EDLs and of SOLs. It will be seen that there is a negative correlation between the space and the muscle weight and that both kinds of muscles show a similar relationship between the space and the weight. In order to obtain an accurate relationship between the space and the weight, calculations were carried out on the following functions: i) $y=k / x+c$, ii) $y=k / x^{2}+c$, iii) $y=k / x^{1 / 2}+c$, iv) $y=k \log x+c$, v) $y=k / \log x+c$, vi) $\log y=k \log x+c$, in which $y$ and $x$ represent the space (ml/100 w. w.) and the muscle weight $(\mathrm{mg})$, respectively, and $k$ and $c$ are constants. The results of calculations are set out in TABLE 3. With the function $y=k / x+c$, which shows, among the six functions, the highest correlation coefficient for the space and the weight in groups of SOLs and EDLs, a further

TABLE 3.

Functions calculated for expressing the relationship between the inulin space and the muscle weight in Wistar-King rats and the correlation coefficients.

\begin{tabular}{l|c|c}
\hline Muscles & $\begin{array}{c}\text { Correlation } \\
\text { coefficients }\end{array}$ & Regression equations \\
\hline (1) $\mathrm{EDL}$ & 0.918 & $y=337.37 / x+5.34$ \\
SOL & 0.940 & $y=365.61 / x+4.99$ \\
EDL+SOL & 0.940 & $y=352.67 / x+5.26$ \\
(2) EDL & 0.888 & $y=8860.0 / x^{2}-7.43$ \\
SOL & 0.932 & $y=7597.6 / x^{2}-8.05$ \\
EDL+SOL & 0.917 & \\
(3) EDL & 0.941 & $y=86.567 / x^{1 / 2}-0.77$ \\
SOL & 0.936 & $y=104.225 / x^{1 / 2}-1.30$ \\
EDL+SOL & 0.937 & \\
(4) EDL & -0.816 & $y=-10.346 \log _{10} x+30.47$ \\
SOL & -0.764 & $y=-10.965 \log _{10} x+31.68$ \\
EDL+SOL & -0.887 & \\
(5) EDL & 0.981 & $y=42.104 / \log _{10} x-11.80$ \\
SOL & 0.935 & $y=48.725 / \log _{10} x-15.69$ \\
EDL+SOL & 0.934 & $y=43.898 / \log _{10} x-12.83$ \\
(6) EDL & -0.916 & $\log _{10} y=-0.463 \log _{10} x+1.89$ \\
SOL & -0.762 & $\log _{10} y=-0.380 \log _{10} x+1.73$ \\
EDL+SOL & -0.924 & \\
\hline
\end{tabular}


calculation was made to know whether or not there is any statistically significant difference between the $k$ for the EDL $(=337.37)$ and that for the SOL $(=365.61)$. No statistically significant difference between SOLs and EDLs was found in the slope of the regression line relating the space to weight. This finding suggests that the dimension of the space in EDLs can be determined by the same function as that expressing the relationship between the inulin

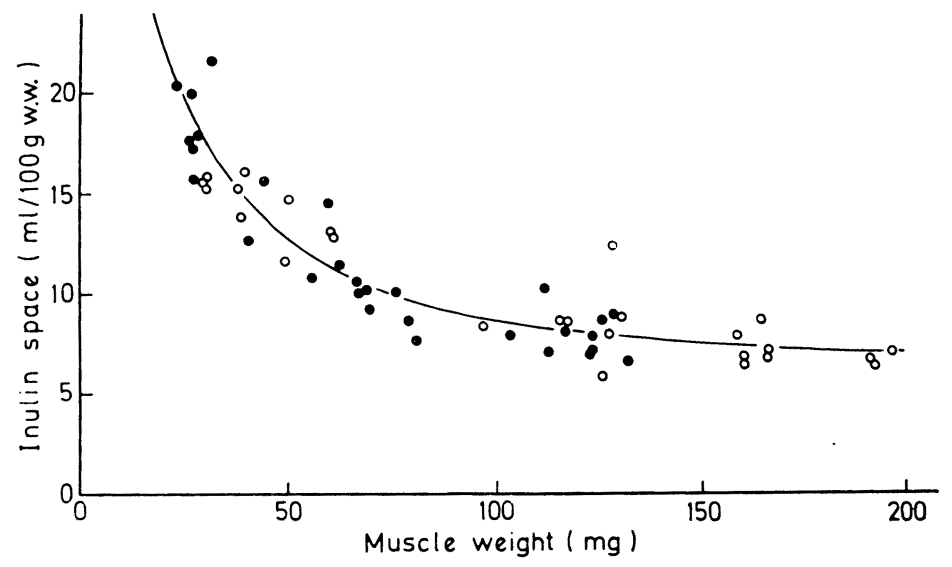

FIG. 3. Relationship between the inulin space of EDLs $(O)$ and SOLs (O) of Wistar-King rats and the muscle weight. The line was drawn according to the equation $y=352.67 / x+5.26$, in which $y$ represents the space and $x$ the weight.

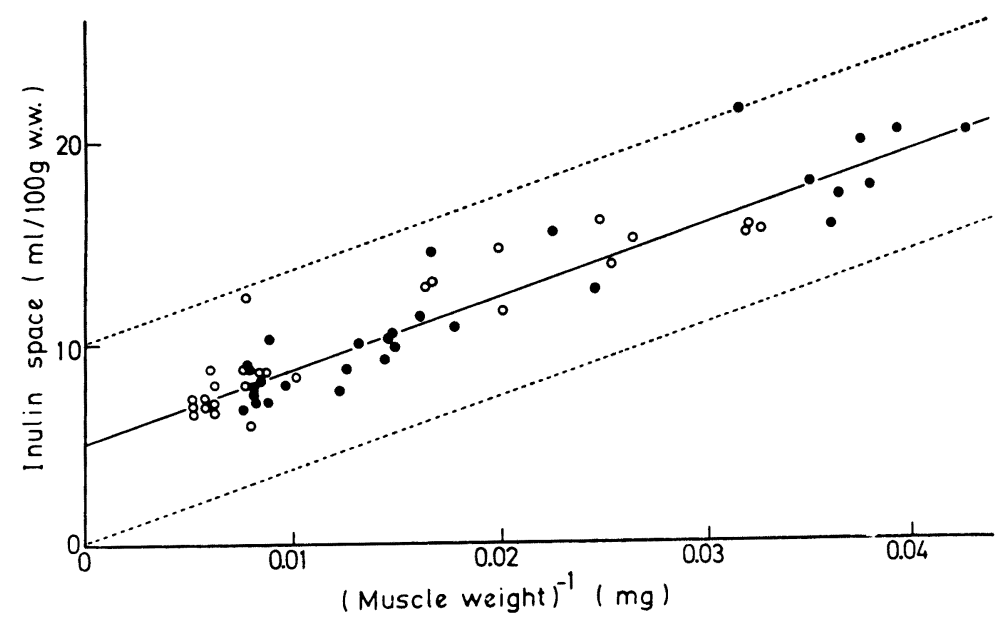

FIG. 4. Relationship between the inulin space and the reciprocal of the weight in EDLs $(O)$ and SOLs $(O)$ of Wistar-King rats. The line indicates the regression equation of the space $(y)$ on the reciprocal of the weight $(1 / x), \mathrm{y}=352.67 / x+5.26$, and \pm 2 S. E. of estimate. 


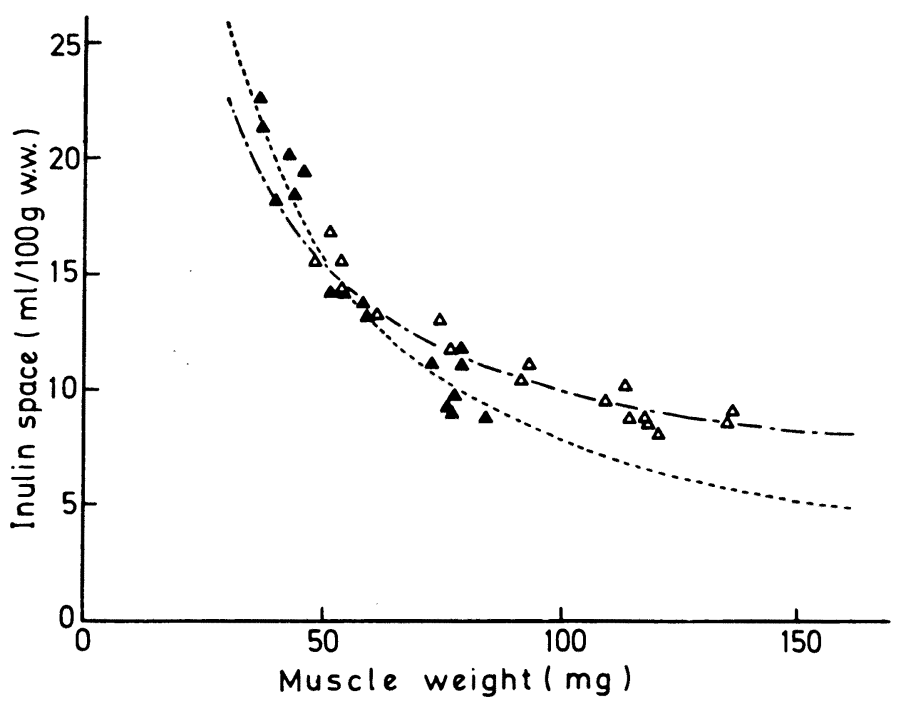

FIG. 5. Relationship between the inulin space of EDLs $(\Delta)$ and SOLs ( $\boldsymbol{\Delta}$ ) of Sprague-Dawley rats and the muscle weight. The line was drawn according to the equation, $y=782.83 / x+0.048$ (EDLs) and $y=541.95 / x+4.645$ (SOLs), in which $y$ is the space and $x$ the weight.

space and the muscle weight in SOLs, or the relationship between the space and the muscle weight is the same despite the difference in the type of muscles. Therefore, in FIG. 4 the inulin space in both EDLs and SOLs was plotted against the reciprocal of the muscle weight.

In muscles of Sprague-Dawley rats, the magnitude of the inulin space ranged from $8.0 \mathrm{ml} / 100 \mathrm{~g}$ w. w. to $22.6 \mathrm{ml} / 100 \mathrm{~g} \mathrm{w}$. w. corresponding to the variation of muscle weights from $36.4 \mathrm{mg}$ to $134.5 \mathrm{mg}$. The negative correlation between the space and the muscle weight was also seen (FIG. 5). The regression equation for the space and the weight was found to be $y=659.80 / x+2.67$ for a group including both SOLs and EDLs, with a high correlation coefficient of 0.955 . However, in the muscles of Sprague-Dawley rats there was a statistically significant difference $(0.05>\mathrm{p}>0.025)$ between the slope of the regression line for the SOL $(y=541.95 / x+4.645)$ and that for the EDL $(y=782.83 / x+0.048)$. This finding is different from the results on muscles of the Wistar-King rats.

\section{DISCUSSION}

The fact, which has been demonstrated in this paper, that the extracellular space of the EDL and SOL shows a significant negative correlation to the muscle weight, is in agreement with previous findings ${ }^{2,69910)}$, and seems to offer a possibility to explain the discrepancy among the values for the inulin 
space of rat muscles reported in previous papers ${ }^{4,8,11,12)}$. The dimensions of the inulin space obtained from the previous investigators were plotted in FIG. 6 against the muscle weight, which was estimated from the age or body weight of rats described in their papers. It will be noted that all values for the inulin space of EDLs and of SOLs derived from various papers ly approximately on a curve relating the space to the muscle weight, which was obtained in the present experiments.

The inulin space of EDLs and of SOLs can be determined by the same function relating the space to the weight of muscles in the Wistar-King rats, whereas in the case of Sprague-Dawley rat this has not been demonstrated. However, further experiments are necessary on the muscles of Sprague-Dawley rats in order to see whether EDLs and SOLs of these rats show a similar relation between the space and the weight to each other, because the number of observations on the inulin space in the Sprague-Dawley rats in the present experiments were not satisfactory for the statistical analyses.

It has also been observed in the present study that the extracellular space of both EDLs and of SOLs in the Sprague-Dawley rats is greater than those in the Wistar-King rats when both kinds of muscles of the same weight are compared with each other (compare FIG. 3 with FIG. 5); similarly the slope of the regression line of the space on the reciprocal of the muscle weight is greater in Sprague-Dawley rats, especially greater in SOLs of Sprague-Dawley rats, than that in Wistar-King ones. This may be attributed to the difference in the rate of increase in total muscle nitrogen concentration, which is almost entirely accounted for by an increase in protein concentration and implies either an increase in the number of muscle fibers or in the cell volume ${ }^{10)}$, and also due to the difference in the mucopolysaccharide and hexosamine contents which are inversely dependent upon the muscle weight ${ }^{7)}$. The latter explanation is considered to be highly probable because the youngest age of rats used in this experiment was one month postnatal and at this age the chemical composition might be nearly in mature ${ }^{2,10)}$.

\section{SUMMARY}

The inulin space of the extensor digitorum longus (EDL) and soleus muscle (SOL) of both Wistar-King and Sprague-Dawley rats was determined. The inulin space of EDLs is in general smaller than that of SOLs in both strains. However, a great variation of the space values was observed for both kinds of muscles; the variability of the space was related to a variation in the muscle weight. It has been found that the dimension of the space is linearly related to the reciprocal of the weight in both kinds of muscles and that in the Wistar-King rats the magnitudes of the space $(y)$ in both muscles are expressed by one and the same function, $y=659.80 / x+2.67$, ( $x$, muscle weight). 
The dry-to-wet-weight ratio was not significantly different between two kinds of muscles of varying weights in both strains of rats.

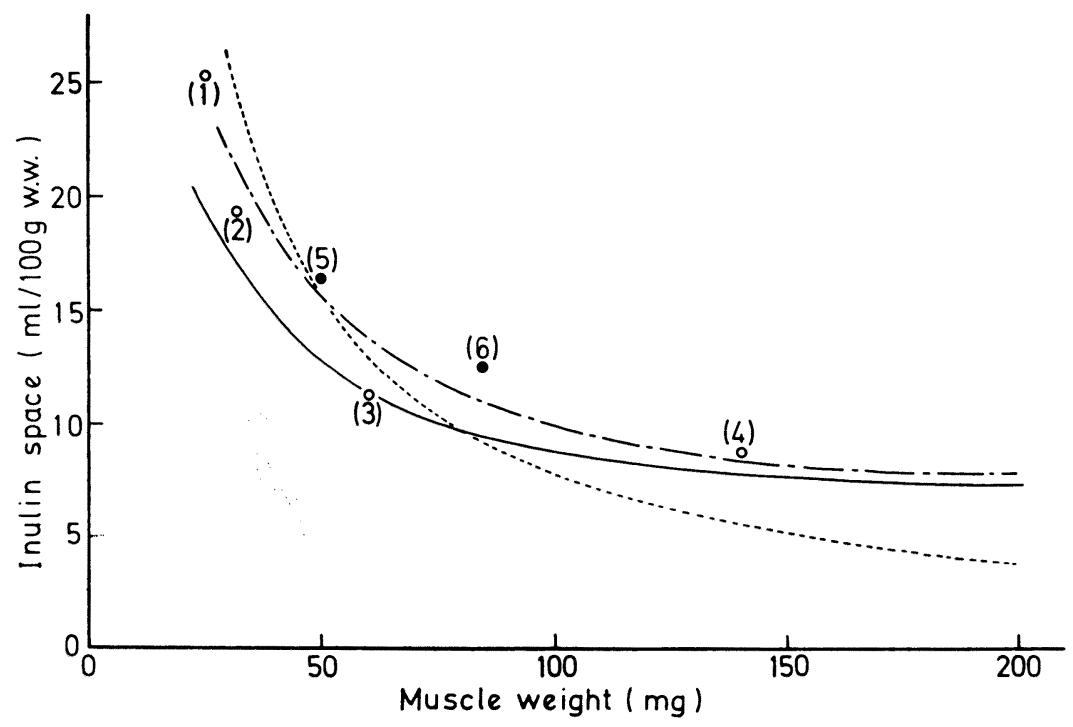

FIG. 6. The inulin spaces of EDLs $(O)$ and SOLs (O) of albino rats, obtained by various authors. (1); Zierler (1959), (2); Zierler et al. (1966), (3); Drahota (1961), (4) ; Sréter and Woo (1963), (5) ; Drahota (1961), (6) ; Sréter and Woo (1963). The weight of muscles used in these studies was not described except in (2), and consequentiy it was estimated from the body weight or age of the rats used. The continuous line represents $y=352.67 / x+5.26$ obtained for both EDLs and SOLs of Wister-King rats, the broken line $y=782.83 / x+0.048$ for EDLs of Sprague-Dawley rats and the dotted line $y=541.95 / x+4.645$ for SOLs of S.D. rats.

The authors are grateful to Professor M. SAto for his helpful advice in carrying out this work and in preparing the manuscript.

\section{REFERENCES}

1) Davson, H. (1964). A Textbook of General Physiology, 3rd ed., p. 369. London: Churchill.

2) Dickerson, J.W. And Widdowson, E. M. (1960). Chemical changes in skeletal muscle during development. Biochem. J. 74, 247-257.

3) Donaldson, H.H. (1924). The Rat. Reference Tables and Data for the Albino Rat (Mus norvegicus albinus) and the Norway Rat (Mus norvegicus). Mem. Wistar Inst. Anat. 6, 2nd ed., p. 1915.

4) Drahota, Z. (1961). The ionic composition of various types of striated muscles. Physiol. Bohemoslov. 10, 160-165.

5) Harrison, H.E. (1942). Proc. Soc. exp. Biol. Med. 49, 111, Cited by. M. Saito in Kodenhisyokukei ni yoru Rinsho-kagaku-kensa (1952), 4th ed., pp. 247-250. Tokyo: Nankodo. 
6) Kusumoto, R. (1963). Measurements of the extracellular space in sartorius muscles of toad Bufo vulgaris Japonicus. Kumamoto med. J. 16, 119-125.

7) Law, R.O. ANd Phelps, C.F. (1966). The size of the sucrose, raffinose, and inulin spaces in the gastrocnemius muscle of the rat. J. Physiol. 186:547-557.

8) SRETER, F. A. AND Woo, G. (1963). Cell water, sodium, and potassium in red and white mammalian muscles. Amer. J. Physiol. 205, 1290-1294.

9) Tasker, P., Simon, S.E., Johnstone, B. M., Shankly, K. H. and Shaw, F.H. (1959). The dimensions of the extracellular space in sartorius muscle. J. gen. Physiol. 43 : 39-53.

10) Vernadakis, A. ANd Woodbury, D. M. (1964). Electrolyte and nitrogen changes in skeletal muscle of developing rats. Amer. J. Physiol. 206, 1365-1368.

11) Z IERLER, K.L. (1959). Effect of insulin on membrane potential and potassium content of rat muscle. Amer. J. Physiol. 197: 515-523.

12) ZiERLER, K. L., Rogus, E. AND HAZLEwOod, C. (1966). Effect of insulin on potassium flux and water and electrolyte content of muscles from normal and from hypophysectomized rats. J. gen. Physiol. 49 : 433-456. 